\title{
Two different domains of the luciferase gene in the heterotrophic dinoflagellate Noctiluca scintillans occur as two separate genes in photosynthetic species
}

\author{
Liyun Liu* and J. Woodland Hastings ${ }^{\dagger}$ \\ Department of Molecular and Cellular Biology, Harvard University, 16 Divinity Avenue, Cambridge, MA 02138 \\ Contributed by J. Woodland Hastings, September 6, 2006
}

This contribution is part of the special series of Inaugural Articles by members of the National Academy of Sciences elected on April $29,2003$.

\begin{abstract}
Noctiluca scintillans, a heterotrophic unarmored unicellular bioluminescent dinoflagellate, occurs widely in the oceans, often as a bloom. Molecular phylogenetic analysis based on $18 \mathrm{~S}$ ribosomal DNA sequences consistently has placed this species on the basal branch of dinoflagellates. Here, we report that the structural organization of its luciferase gene is strikingly different from that of the seven luminous species previously characterized, all of which are photosynthetic. The Noctiluca gene codes for a polypeptide that consists of two distinct but contiguous domains. One, which is located in the $\mathrm{N}$-terminal portion, is shorter than but similar in sequence to the individual domains of the three-domain luciferases found in all other luminous dinoflagellates studied. The other, situated in the C-terminal part, has sequence similarity to the luciferin-binding protein of the luminous dinoflagellate Lingulodinium polyedrum, encoded there by a separate gene. Western analysis shows that the native protein has the same size $(\approx 100$ $\mathrm{kDa}$ ) as the heterologously expressed polypeptide, indicating that it is not a polyprotein. Thus, sequences found in two proteins in the L. polyedrum bioluminescence system are present in a single polypeptide in Noctiluca.
\end{abstract}

bioluminescence | luciferin-binding protein | gene fusion | gene fission | domain duplication

$T^{\mathrm{t}}$ he bioluminescent systems of seven previously studied bioluminescent marine dinoflagellates have been found to be similar, but unusual in several respects, and very different from any of the other groups of luminous organisms (1). In the case of Lingulodinium polyedrum (Lp, formerly Gonyaulax polyedra), light is emitted as flashes from specialized organelles called scintillons, which are formed as outpocketings from the cytoplasm into the acidic vacuole $(2,3)$. The scintillons contain the three components required for light emission: dinoflagellate luciferase (LCF) (4), its luciferin substrate, and a luciferinbinding protein (LBP) (5).

Lp luciferase $\left(M_{\mathrm{r}}, \approx 137 \mathrm{kDa}\right)$ has an internal triplication, thus three homologous domains within a single molecule, each of which, when isolated as a separate peptide, is catalytically active in vitro (6). There is also an N-terminal sequence of $\approx 100$ aa of unknown function. LBP is a smaller protein $\left(M_{\mathrm{r}}, \approx 75 \mathrm{kDa}\right)$, whose $\mathrm{N}$-terminal $\approx 100$ aa has a sequence identity of $\approx 50 \%$ with the corresponding luciferase region (7). The activities of both proteins are strongly regulated by $\mathrm{pH}(8)$.

In six other photosynthetic dinoflagellates, the structures of the luciferases were found to be essentially the same as in Lp, and all were found to occur in multiple and tandem copies, albeit with very different intergenic sequences $(9,10)$. In some of these species, a luciferin-binding protein has not yet been found, but in vitro, all react to emit light with the luciferin of Pyrocystis lunula (Pl), which was established to be an open tetrapyrrole (11) and will be called dinoflagellate luciferin.

Based on 18S ribosomal DNA, the heterotrophic unarmored species Noctiluca scintillans (Ns) is phylogenetically distant (12), but cell extracts also were shown to react with dinoflagellate luciferin to give light. This emission allowed the identification of a luciferase clone whose expressed protein has a very interesting structure. It lacks the N-terminal $\approx 100$-aa sequence present in the other seven dinoflagellate luciferases and is composed of two major domains. The $\mathrm{N}$-terminal region codes for a protein with luciferase activity and has sequence similarity to the individual domains of the three-domain luciferase of Lp, whereas the C-terminal region has sequence similarity to the LBP of Lp.

In the course of this work, it also was discovered that both the LBP region identified in Noctiluca and the Lp LBP have an internal repeat structure with four domains. However, these domains are less well conserved among themselves than are the three LCF domains of the seven photosynthetic dinoflagellates.

\section{Results and Discussion}

Molecular Cloning of the Full-Length Noctiluca Luciferase Gene and the Two-Domain Protein. Because Noctiluca luciferase in crude extracts cross-reacts biochemically with dinoflagellate luciferin to emit light, we screened a Noctiluca cDNA expression library for light emission with added Pyrocystis luciferin. From $\approx 2 \times 10^{4}$ colonies, two were found to emit light. Subsequent sequencing of plasmid DNA from the two showed that they were identical, both lacking $5^{\prime}$ and $3^{\prime}$ untranslated regions, poly(A) tail, and portions of $\mathrm{N}$ - and $\mathrm{C}$-terminal regions of the ORF.

We cloned the full-length gene and the intergenic sequence by PCR amplification from genomic DNA by using primers derived from the partial luciferase cDNA. A search of the National Center for Biotechnology Information database by BLAST revealed that the $\mathrm{N}$-terminal part of the Noctiluca sequence shares similarity only to the single domains of all other dinoflagellate luciferases, whereas its C-terminal part has sequence similarity only to the LBP of the dinoflagellate Lp. Various combinations of PCR amplification from genomic DNA ruled out the possibility that the chimeric feature of this luciferase gene might have resulted from cloning artifacts.

As is known for luciferase genes in the other dinoflagellates (10), the Noctiluca gene also occurs as tandem copies (Fig. 1). However, the intergenic nucleotide sequence (GenBank acces-

\footnotetext{
Author contributions: L.L. and J.W.H. designed research; L.L. performed research; L.L. and J.W.H. analyzed data; and L.L. and J.W.H. wrote the paper.

The authors declare no conflict of interest.

Abbreviations: LBP, luciferin binding protein; LCF, luciferase; Lp, Lingulodinium polyedrum; Ns, Noctiluca scintillans; Pl, Pyrocystis lunula; Pr, Protoceratium reticulatum.

Data deposition: The sequence reported in this paper has been deposited in the GenBank database (accession no. 828400).

See accompanying Profile on page 693.

*Present address: Department of Biology, California State University, Northridge, CA 91330

†To whom correspondence should be addressed. E-mail: hastings@fas.harvard.edu.

() 2006 by The National Academy of Sciences of the USA
} 
Ns LCF

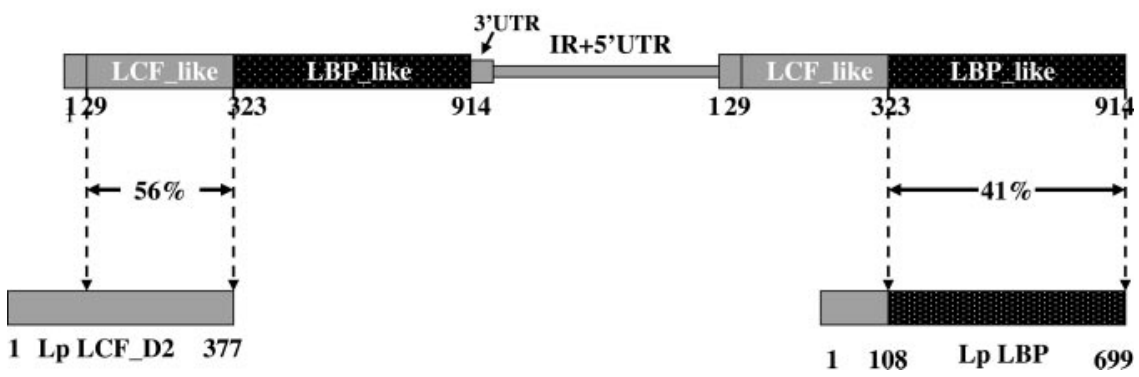

Fig. 1. A schematic representation showing the genomic structure of Ns /cf genes and the domain organization of their predicted proteins in comparison with the second domain of Lp LCF and Lp LBP. At least two copies of the Ns Icf genes are tandemly arranged in a head-to-tail fashion, each consisting of 4,360 bp. The precise boundary between the intergenic region and 5' UTR was not precisely mapped, and together they account for 1,518 bp. The 3' UTR of the Ns Icf is only 97 bp long, therefore, much shorter than the 3' UTRs of Icf genes of seven photosynthetic dinoflagellates, which range from 194 to 432 bp. The largest ORF of Ns Icf predicts a protein of 914 aa with two major domains, an N-terminal luciferase-like (LCF-like) domain and a C-terminal luciferin-binding protein-like (LBP-like) domain. The LCF-like domain shares a $56 \%$ sequence identity with but is shorter at the $\mathrm{N}$ terminus by 60 aa residues than the individual domains of Lp LCF. The LBP-like domain of 591 aa residues is $41 \%$ identical with the comparable region of Lp LBP. No significant similarity was found between the most $\mathrm{N}$-terminal sequence of 29 aa residues of the Ns LCF and any sequences in the database.

sion no. 828400) has no similarity to those of any of the other dinoflagellate tandem genes reported, which themselves are different from each other.

As also shown in Fig. 1, the full-length Noctiluca protein possesses a short N-terminal sequence of 29 aa residues followed by two domains, referred to as the luciferase-like and the LBP-like domains, which are linked by a sequence of 11 aa residues. No significant similarity was found between the 29-aa N-terminal Noctiluca sequence and the $\approx 100$-aa N-terminal sequence of any of the seven other dinoflagellate luciferases, or of Lp LBP, or any other sequence in the GenBank.

Noctiluca Luciferase-Like Domain Protein. The luciferase-like domain of Noctiluca shares amino acid identities of $52-56 \%$ with those of the individual domains of the seven other dinoflagellate luciferases, which are 68-84\% identical among themselves (three of which are tabulated; Table 1). Compared with the domains of the other luciferases, the Noctiluca domain is shorter by $\approx 60$ aa at the $\mathrm{N}$ terminus, thus lacking three of the four N-terminal histidines present in Lp luciferase, which have been shown to be critical for the regulation of its activity by $\mathrm{pH}$ (13). Based on 18S ribosomal DNA analysis (12), Noctiluca is more primitive than any other previously studied bioluminescent dinoflagellate species. A phylogenetic tree of its LCF domain and the individual domains of the other seven lucif- erases, based on the protein sequences (Fig. 2), is consistent with this conclusion.

Previous studies revealed that the amount of bias in codon usage varies in the central regions of the domains of the luciferases of the seven photosynthetic dinoflagellates $(9,10)$. The effective numbers of codons is a measure of codon biases (higher value, lower bias). This value is lowest for Lp luciferase $(\approx 33$ ) and highest for Pl luciferase $(\approx 50)$; the corresponding value for the Noctiluca luciferase-like domain (55) is even higher. Guanosine and cytosine account for only $40 \%$ at the third position of its codons, a value that is far lower than that for the seven other luciferases (64-87\%). Thus, the biased usage of cytosine in the central part of Lp luciferase domains, which is correlated with a low synonymous substitution rate in that region and, possibly, plays a role in the observed translational regulation, is not found in this more primitive Noctiluca species.

Noctiluca LBP-Like Domain Protein. The Noctiluca LBP-like region has a relatively low sequence identity with the Lp LBP (41\% at the amino acid level). Unexpectedly, it was found to contain four internal repeats, based on analysis by an improved SmithWaterman algorithm (14). Four internal repeats also were detected in the Lp LBP, a feature that previously had gone unnoticed. An alignment of internal repeats of the LBP-like region in Noctiluca and Lp is shown in Fig. 3. Half of the amino acids that are fully conserved in both species are charged

Table 1. A pairwise comparison of Ns LCF-like domain with the individual domains of luciferases from three representative photosynthetic species

\begin{tabular}{lcrrrrrrrrr} 
Domains & Ns LCF-like & AtD1 & LpD1 & PID1 & AtD2 & LpD2 & PID2 & AtD3 & LpD3 & PID3 \\
\hline Ns LCF-like & 100 & 54 & 55 & 56 & 56 & 56 & 56 & 52 & 55 & 54 \\
AtD1 & & 100 & 82 & 77 & 75 & 72 & 71 & 72 & 73 & 74 \\
LpD1 & & & 100 & 81 & 73 & 75 & 74 & 72 & 77 & 74 \\
PID1 & & & & 100 & 69 & 74 & 72 & 68 & 73 & 70 \\
AtD2 & & & & & 100 & 80 & 81 & 78 & 76 & 78 \\
LpD2 & & & & & & 100 & 84 & 74 & 81 & 75 \\
PID2 & & & & & & 100 & 71 & 79 & 75 \\
AtD3 & & & & & & & 100 & 80 & 83 \\
LpD3 & & & & & & & & 100 & 84 \\
PID3 & & & & & & & & & 100 \\
\hline
\end{tabular}

Values shown are in \%. The amino acid sequence identities of the Ns LCF-like domain with those of the other three fall in the range of $54-56 \%$, lower than $68-84 \%$, which are found among the latter themselves. At, Alexandrium tamarense. 


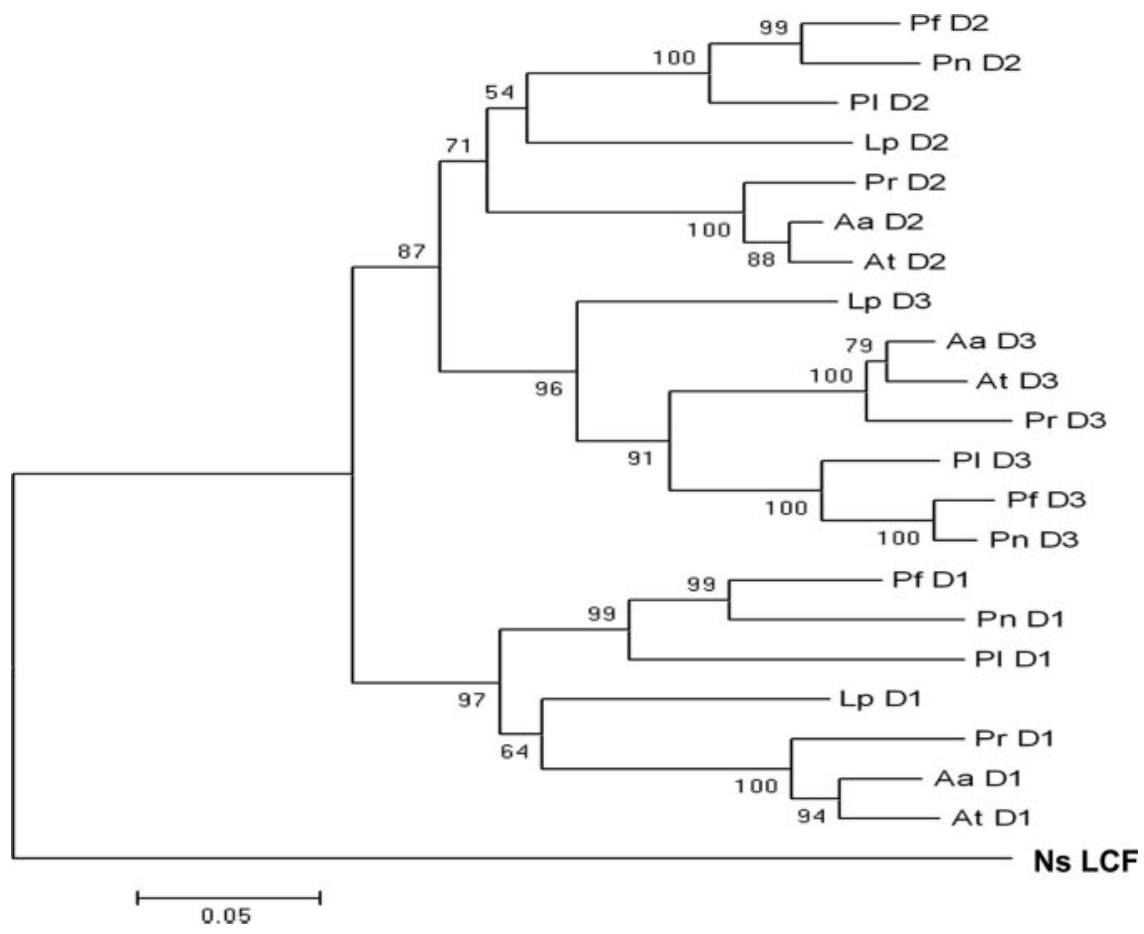

Fig. 2. A distance tree based on the protein sequences and generated by using a MEGA program as described in Materials and Methods. (Scale bar: 0.05 substitutions per site.) The numbers at the nodes of the tree are bootstrap values, which measure the robustness of the support for each particular node.

residues (three arginines, two glutamic acids, and one aspartic acids), marked by arrows in Fig. 3. The overall identities of the LBP domains are quite low, falling in the range of 5-20\% (Table 2). Phylogenetic analysis indicates that the corresponding domains of the two LBPs are grouped together, rather than different domains within a given species (Fig. 4), a feature that also was found for the intramolecular domains of the seven luciferases (9).

Noctiluca Luciferase Protein in Cell Extracts. On Western blots of cell extracts, a single band of $\approx 100 \mathrm{kDa}$ was detected with the Lp luciferase antibody (Fig. 5, lane 1), whereas two bands were seen with the Lp LBP antibody, with sizes corresponding to the full-length molecule $(\approx 100 \mathrm{kDa})$ and to the LBP-like domain ( $\approx 65 \mathrm{kDa}$ ) (Fig. 5, lane 2). Despite the presence of an added protease inhibitor mixture in the extraction buffer, the $\approx 65 \mathrm{kDa}$ band could have resulted from a proteolytic cleavage during extraction in the region of the linker. In that case, however, the luciferase-like part of the molecule also should be seen with the luciferase antibody, but it was not. It is also possible, but improbable, that this $65-\mathrm{kDa}$ band represents some antigenically cross-reacting material, not related to the luciferase system. Finally, it is possible that in Noctiluca the lbp is also structured as a separate gene, as in the photosynthetic species, responsible for expressing the LBP protein seen on the Western blot. If so, the protein might function in Noctiluca as in Lp, sequestering the luciferin within the organelle at high $\mathrm{pH}$ and releasing it at a low $\mathrm{pH}$. But it might have a different function, for example, as a cytoplasmic reservoir for luciferin. In any event, the presence of additional genes involved in the functioning of the bioluminescence system cannot be excluded.

As shown in Fig. 6A, Noctiluca cell extracts made at $\mathrm{pH} 8$ emit luminescence simply upon shifting the $\mathrm{pH}$ to 6 (without added luciferin) and show a sharp $\mathrm{pH}$ dependence, peaking at $\mathrm{pH}$ 6.0, a feature that also had been described by Nawata and Siboaoka (15); this behavior is similar to that of Lp cell extracts. In both cases, the luciferins are endogenous, but their exact structures may be different.

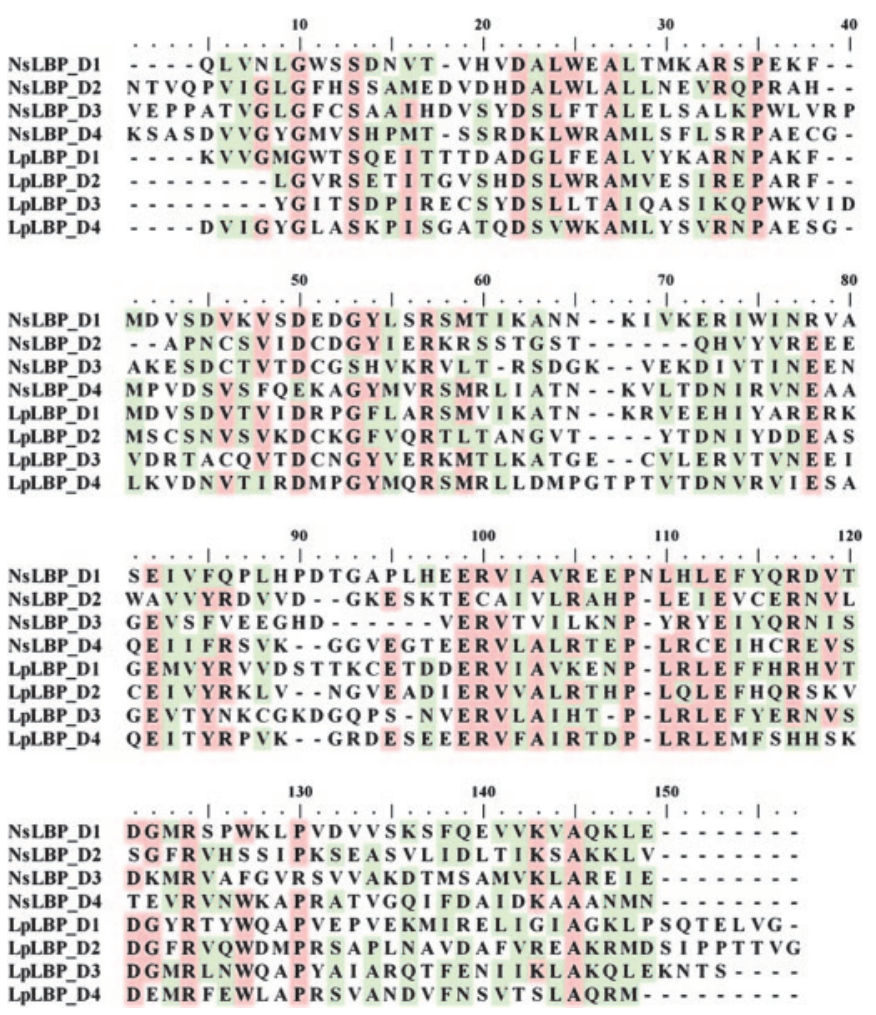

Fig. 3. An alignment of four internal repeats of Ns and Lp LBPs. The residues shaded in red are identical in a majority of the sequences, whereas those in green are conserved in a majority. Arrows mark the charged residues, which are present in all of the sequences compared. 
Table 2. A pairwise comparison of the four repeats of Ns LBP-like domain and Lp LBP

\begin{tabular}{lcccccccc} 
Repeats & NsLBP_D1 & NsLBP_D2 & NsLBP_D3 & NsLBP_D4 & LpLBP_D1 & LpLBP_D2 & LpLBP_D3 & LpLBP_D4 \\
\hline NsLBP_D1 & 100 & 5.0 & 5.7 & 6.3 & 19.5 & 7.8 & 17.3 & 7.1 \\
NsLBP_D2 & & 100 & 13.6 & 10.5 & 8.3 & 22.1 & 13.8 & 6.4 \\
NsLBP_D3 & & & 100 & 7.0 & 6.9 & 7.1 & 4.1 & 9.2 \\
NsLBP_D4 & & & & 100 & 5.5 & 4.9 & 5.5 & 7.0 \\
LpLBP_D1 & & & & & 100 & 20.2 & 21.5 & 11.1 \\
LpLBP_D2 & & & & & & 100 & 13.1 & 12.8 \\
LpLBP_D3 & & & & & & & 100 & 18.0 \\
LpLBP_D4 & & & & & & & & 100 \\
\hline
\end{tabular}

Values shown are in \%.

Expressed Protein from Constructs of the Noctiluca Luciferase Gene. We expressed the full-length Noctiluca luciferase gene in SF21 insect cells as a FLAG-tagged protein (at the C-terminal end) by using a Gateway baculovirus expression system. Western blots by using anti-FLAG antibodies resulted in a major band at $\approx 100$ $\mathrm{kDa}$, corresponding to the predicted size of the full-length protein, and a minor band at $\approx 65 \mathrm{kDa}$, corresponding to the size of the LBP-like sequence (Fig. 5, lane 3). This minor band could be due to proteolysis in such preparations, as was also suggested as a possible explanation for the $\approx 65 \mathrm{kDa}$ band in crude extracts (Fig. 5, lane 2). A third, and very minor band $(\approx 5 \%$ of total protein) at $\approx 80 \mathrm{kDa}$, considered to be an unknown impurity, also was present.

The construct, containing the $l b p$-like domain itself, was expressed poorly in both bacterial and insect cells, but well enough to be verified by Western blots with anti-FLAG antibody (Fig. 5, lane 4). Its activity, if any (see below), was less than the detection limit of our assay.

In contrast to cell extracts, the activity of the full-length heterologously expressed protein with Pyrocystis luciferin showed only a modest dependence on $\mathrm{pH}$. Because three of the four $\mathrm{N}$-terminal histidines responsible for the $\mathrm{pH}$ regulation of Lp luciferase are absent in the Noctiluca lucferase-like sequence, it was not expected that this part of the molecule would contribute to the $\mathrm{pH}$ effect. Whether the LBP-like domain does so was not determined. It has the same approximate size as the separate LBP protein of Lp, and the structures of both appear to be due to an internal quadruplication of a short sequence, a previously undiscovered and intriguing feature. We expressed the LBP-like Noctiluca sequence separately and tested its ability to inhibit the $\mathrm{Lp}$ reaction at $\mathrm{pH} 8$ by using D2 luciferase (see
Methods). No inhibitory activity was observed, but the concentrations available were low; such a test would be more meaningful if carried out with Noctiluca luciferase.

Evolution of Luciferases. The formation and evolution of genes can involve fusion, fission, or both $(16,17)$. Thus, the ancestral system may have had two genes, which fused in the Noctiluca lineage and remained in the branch leading to the photosynthetic species. Alternatively, based on the more primitive status of Noctiluca, its luciferase gene can be viewed as more similar to the ancestral gene in dinoflagellates, which then split in giving rise to the photosynthetic species.

Taking the latter view, it may be postulated that the ancestral gene coded for a single two-domain protein in which, before the reaction of luciferin with oxygen, its LBP region binds luciferin and then releases it to the luciferase-like catalytic site in a $\mathrm{pH}$-dependent step. A system such as in Lp later evolved after these two domains underwent fission to form two genes, with the different functions in separate proteins, with the catalytic component having developed an additional and supportive $\mathrm{pH}$ regulatory function. In Lp, both proteins are packaged together in subcellular organelles, probably in some sort of supramolecular complex. The more primitive Noctiluca system also is localized in subcellular organelles (18) and, as demonstrated by Eckert (19), is triggered by a conducted action potential in the vacuolar (tonoplast) membrane. Although these organelles may be similar to the Lp scintillons $(20)$, both emitting brief $(<100 \mathrm{msec})$ bright flashes, their ultrastructure has not been elucidated.

Dinoflagellate Luciferins. As mentioned earlier, the so-called dinoflagellate luciferin used in all of the experiments reported

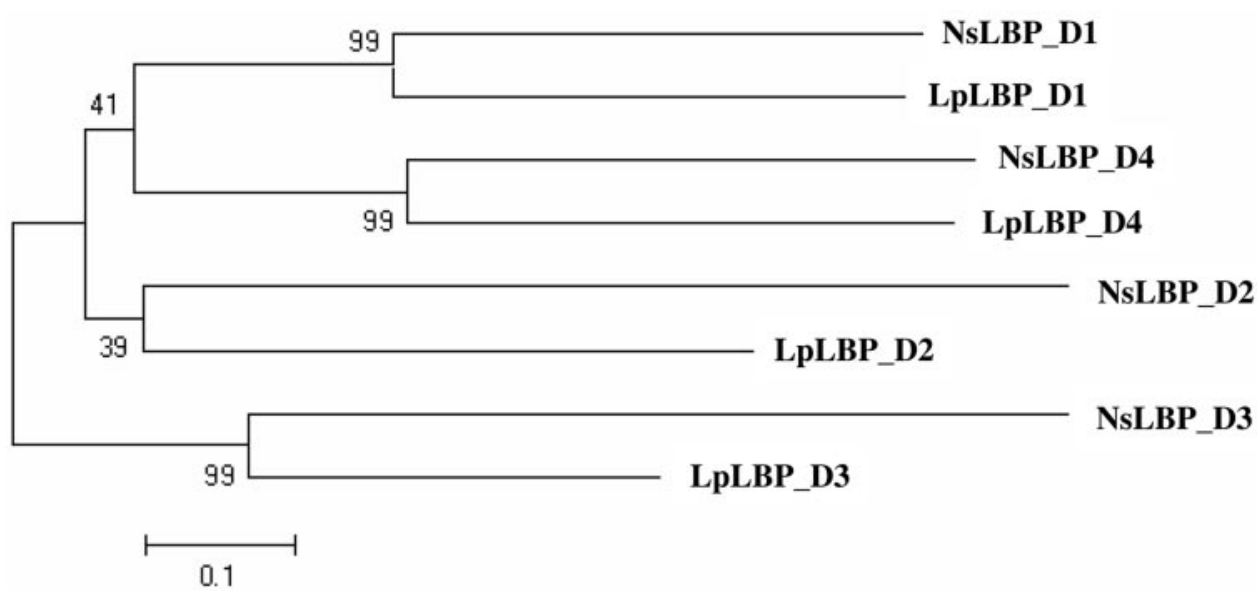

Fig. 4. A phylogenetic tree showing a relationship of duplicated repeats of Ns LBP-like domain and Lp LBP. On this tree, corresponding domains of the LBPs of different species are grouped together. All nodes are well supported except for the one that defines the clade of the second repeats, which has a bootstrap value of only $39 \%$. (Scale bar: 0.1 substitutions per site.) 


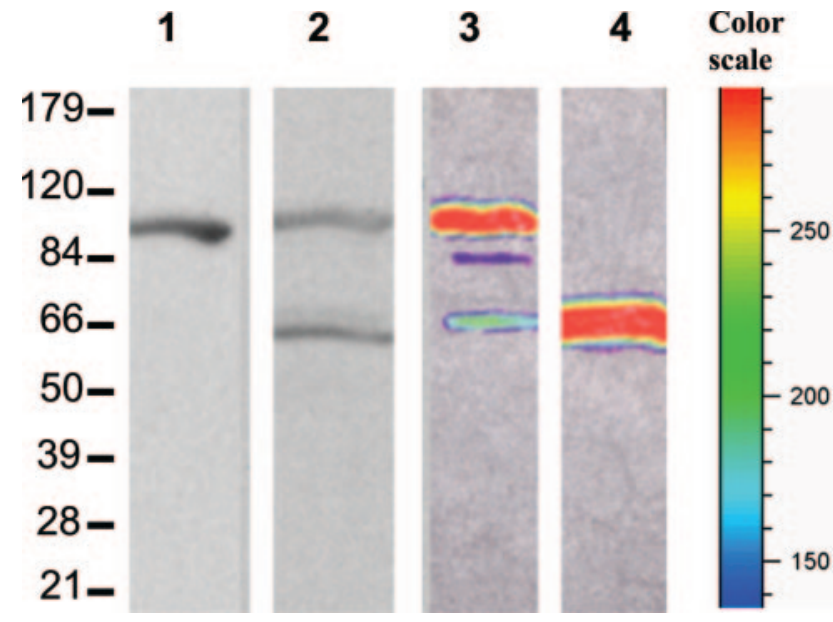

Fig. 5. Western blotting analysis of the native and recombinant Ns LCFs. Native Ns LCF was isolated from frozen cells and, after SDS/PAGE separation and blotting onto the nitrocellulose membrane, was probed by either anti-Lp luciferase (lane 1) or anti-Lp LBP (lane 2). FLAG-tagged Ns full-length LCF (lane 3) and its LBP-like domain (lane 4) were expressed in SF21 cells by using a bacuolovirus expression system and extracted for Western blotting analysis by using anti-FLAG antibody. Each of the lanes received $\approx 10 \mu \mathrm{g}$ of total protein Relative intensities of the bands shown in lane 3 and 4 correspond to the colors indicated by the color scale lane.

here is, in truth, Pl luciferin. It is certainly possible that Ns luciferin differs in small ways from $\mathrm{Pl}$ luciferin. If so, it may explain the difference in $\mathrm{pH}$ dependency of emission between native Ns luciferase in cell extracts and full-length Ns recombinant luciferase (Fig. 6). For example, at high $\mathrm{pH}$ native Ns luciferin could bind tightly to the LBP part of Ns luciferase, thus preventing its reaction with the luciferase-like domain, whereas Pl luciferin might remain free and able to react. The luciferaselike region is expected to lack $\mathrm{pH}$-regulatory capability, because three of the four histidines responsible for this regulation are lacking. Minor structural differences between the luciferins also could affect the quantum efficiency of the bioluminescence reaction.

Indeed, although it has been proposed that the tetrapyrrole luciferin is derived from chlorophyll, the source and/or biosynthetic pathway of dinoflagellate luciferin is not actually known for any species. Cross-reactions of luciferins and luciferases occur in both directions with all species tested, but only the structure of Pyrocystis luciferin has been established. The origin of the luciferin in Noctiluca, a heterotrophic species, is of special interest. If it also is derived from chlorophyll, the parent molecule surely must be acquired by ingestion of a chlorophyllor luciferin-containing prey. A luciferin substrate is known to be acquired nutritionally in some animals, notably the midshipman fish, where the luciferin is obtained by the ingestion of bioluminescent crustaceans (21).

\section{Materials and Methods}

Collection. Cells of Noctiluca, ranging in diameter from 400 to 700 $\mu \mathrm{m}$, were harvested from surface water of the Gulf of Mexico off the pier of the Marine Science Institute of the University of Texas-Austin at Port Aransas by using a 50-cm-diameter nylon net with a pore size of $158 \mu \mathrm{m}$. Other larger-sized planktonic organisms were removed with a 1-mm pore-size filter, and the filtrate was poured into a separatory funnel. Because the Noctiluca buoyant density is less than that of sea water, this and other material could be drained off, leaving the cells on the surface. For further purification, the cells were resuspended in sea water, layered again at the surface by centrifugation at $1,000 \times g$ for 10
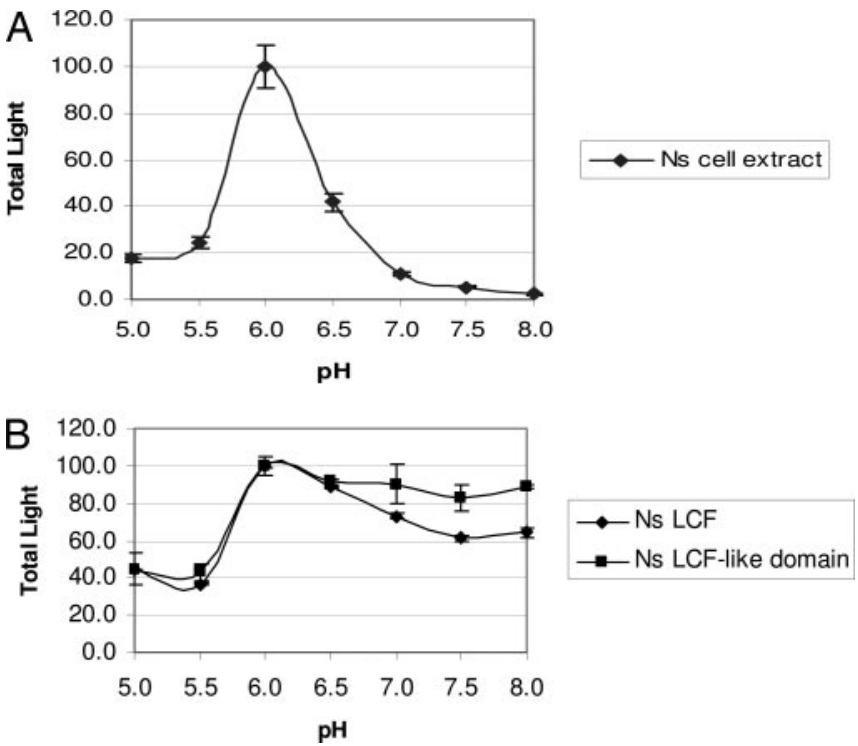

Fig. 6. $\mathrm{pH}$ dependence of native and recombinant Noctiluca luciferases. Luciferase activity of the cell extract is strongly $\mathrm{pH}$-dependent $(A)$, whereas activity of the expressed luciferase-like domain with PI luciferin is less so $(B)$.

min at room temperature, and concentrated on a nylon filter of 5 -cm diameter with a pore size of $158 \mu \mathrm{m}$. The excess water was absorbed by paper towels placed underneath the filter. The cells were transferred to $15-\mathrm{ml}$ Falcon plastic tubes, frozen in liquid nitrogen, shipped back to our laboratory on dry ice, and stored at $-80^{\circ} \mathrm{C}$ until use.

Molecular Cloning of the Luciferase Gene. For isolating genomic DNA and total RNA, the cells were homogenized in liquid nitrogen, followed by phenol and chloroform extraction as described in ref. 22. mRNA was selected by using oligo(dT) paramagnetic particles (Promega, Madison, WI), converted into DNA, and inserted to $\lambda$ ZAPII vector (Stratagene, La Jolla, CA) to generate a cDNA library. The mass excision of the phage library and the plating of the resultant phagemid library were performed according to the manufacturer's manual. Protein expression was induced by incubation overnight with $1 \mathrm{mM}$ IPTG at $4^{\circ} \mathrm{C}$. After being transferred onto a nitrocellulose membrane, the colonies were lysed in situ by overlaying the membrane on $3 \mathrm{MM}$ paper (Millipore, Billerica, MA) that had been presoaked in dinoflagellate luciferin with $50 \mathrm{mM}$ sodium phosphate, $\mathrm{pH}$ 8.0/5 mM 2-mercaptoethanol/0.05\% Triton $\mathrm{X}-100$. The Triton $\mathrm{X}-100$ is essential for effective lysis of bacterial cells. Light-emitting colonies were identified by imaging with a CCD camera system (IVIS; Xenogen Corp., Alameda, $\mathrm{CA}$ ), and the cDNA clones were isolated.

To isolate the full-length cDNA, nested PCRs were carried out with the cDNA library as a template by using two specific primers based on the sequence of the cDNA clones in the sense orientation and $\mathrm{T} 7$ and M13 reverse primers in the antisense orientation. The longest PCR product was sequenced and found to include much of the ORF with the stop codon, along with the 3' UTR and poly(A) tail. A similar approach was used to determine the additional $5^{\prime}$ end sequence and the start codon.

Pairs of sense and antisense primers then were designed based on the $3^{\prime}$ UTR and 5' UTR, respectively, and used for PCR amplification of the intergenic region of tandem copies from the genomic DNA. All PCR products were cloned into the TA cloning vector, pCR II (Invitrogen, Carlsbad, CA) and sequenced. The assembly of the full-length sequence containing the cDNA and the intergenic sequence was done by using the 
Cap Contig Assembly program in the software BioEdit (Ibis Therapeutics, Carlsbad, CA). The continuity of the cDNA and intergenic region were confirmed by PCR amplification of the genomic DNA by using several combinations of primers.

Phylogenetic and Bioinformatic Analysis. Four intramolecular repeats of both the Noctiluca LBP-like domain and Lp LBP were detected and defined by using a program available from the website (http://nihserver.mbi.ucla.edu/Repeats). Alignments of protein sequences were done with CLUSTAL W. Phylogenetic trees were constructed based on the neighbor-joining method implemented in MEGA 3.1 (23). The selection of specific parameters for the tree construction and other bioinformatic analysis were done as described in ref. 9.

Production of Recombinant Proteins in Bacterial and Insect Cells. The full-length gene and luciferase domain of the Noctiluca luciferase were amplified from the genomic DNA by PCR with PFU DNA polymerase (Stratagene). A sequence coding for the hydrophilic octapeptide, DYKDDDDK, was incorporated into the antisense primers to allow the quality and quantity of protein expression to be monitored by anti-FLAG antibody. The PCR products were cloned into pENTR-D (Invitrogen). After confirmation of the insert orientation and correct conjunctions, the luciferase domain was exchanged into pDEST_15 for GST fusion protein expression in E. coli, whereas the full-length gene was exchanged into pDEST_10 for histidine tagged protein expression in insect (SF21) cells. The remaining steps for protein production with pDEST were performed essentially as described in the Gateway system manual available from the manufacturer (Invitrogen). Cell lysates were used for assays of luciferase activity of both the luciferase-like domain and the full-length luciferase protein.

The Noctiluca LBP-like domain and Lp LBP gene were cloned separately into pQE30 (Qiagen, Valencia, CA) by restriction enzymes and expressed as a six $\mathrm{N}$-terminal histidine-tagged fusion proteins. The recombinant proteins were produced in an E. coli strain, M15 (prep4) bound to Ni-NTA resin, and eluted by $250 \mathrm{mM}$ imidazole as directed in the instructions (Qiagen).

The second luciferase domain of Lp with its four N-terminal histidines replaced by alanines had been prepared in a previous study (13) and was used here as the $\mathrm{pH}$ 8-active luciferase for measuring LBP binding activity, expected to have a maximum at that $\mathrm{pH}$.

Antibody Production and Western Blotting Analysis. Polyclonal antibodies against dinoflagellate proteins were produced by Sera Source, Inc. (Royalston, MA). For LBP, $\approx 1 \mathrm{mg}$ of the histidinetagged recombinant protein $(>95 \%$ pure) was injected into each

1. Wilson T, Hastings JW (1998) Annu Rev Cell Dev Biol 14:197-230.

2. Fogel M, Hastings JW (1972) Proc Natl Acad Sci USA 69:690-693.

3. Nicolas M-T, Bassot J-M, Johnson CH, Hastings JW (1987) in Lecture Notes on Coastal and Estuarine Studies: Immunochemical Approaches to Coastal, Estuarine and Oceanographic Questions, eds Yentsch CM, Mague FC, Horan PK (Springer, New York), pp 278-282.

4. Dunlap J, Hastings JW (1981) J Biol Chem 256:10509-10518.

5. Fogel M, Hastings JW (1971) Arch Biochem Biophys 142:310-321.

6. Li L, Hong R, Hastings JW (1997) Proc Natl Acad Sci USA 94:8954-8958.

7. Lee DH, Mittag M, Sczekan S, Morse D, Hastings JW (1993) J Biol Chem 268:8842-8850.

8. Morse DM, Pappenheimer AM, Hastings JW (1989) J Biol Chem 264:1182211826.

9. Liu L, Wilson T, Hastings JW (2004) Proc Natl Acad Sci USA 101:16555-16560.

10. Liu L, Hastings JW (2006) J Phycol 42:96-103.

11. Nakamura H, Kishi Y, Shimomura O, Morse D, Hastings JW (1989) J Am Chem Soc 111:7607-7611.

12. Edvardsen B, Shalchian-Tabrizi K, Jakobsen KS, Medlin LK, Dahl E, Brubak S, Paasche E (2003) J Phycol 39:395-408. of two rabbits. These antibodies were affinity-purified by incubating the serum with Lp LBP protein separated by SDS/PAGE and immobilized on nitrocellulose strips, followed by extensive washing with $0.05 \%$ Triton $\mathrm{X}-100 / 1 \times \mathrm{PBS}$ and elution at a reduced $\mathrm{pH}$ (2.5) after addition of glycine (24). Processing of the Lp luciferase antibody was done as described in ref. 25. Proteins were extracted from frozen Noctiluca cells and used for Western blot analysis with either the affinity-purified Lp luciferase antibodies or the Lp LBP antibodies by following the protocol described in ref. 10. The integrity of proteins expressed in the bacteria or insect cells was determined by Western blot analyses with anti-FLAG antibody (Sigma, St. Louis, MO) or affinitypurified antibodies against either Lp luciferase or LBP. The pseudocolored chemiluminescent images of the Western blots were obtained with a CCD camera system (IVIS; Xenogen Corp.) based on HRP activity.

Luciferin, Luciferase, and LBP Assays. Crude dinoflagellate luciferin was prepared by immersing freshly harvested cells of $P$. lunula $(0.5 \mathrm{~g}$ of wet weight) in $10 \mathrm{ml}$ of boiling $50 \mathrm{mM}$ sodium phosphate, $\mathrm{pH} 8.0 / 5 \mathrm{mM}$ 2-mercaptoethanol/0.05\% Triton $\mathrm{X}-100$ for $10 \mathrm{~min}$, followed by cooling on ice and centrifugation. To measure luciferase activity, an aliquot of $\approx 10-50 \mu \mathrm{g}$ of total protein in $10-50 \mu \mathrm{l}$ in $50 \mathrm{mM}$ phosphate buffer and 5-20 $\mu \mathrm{l}$ of crude dinoflagellate luciferin were spotted at separate places on the bottom of a $10-\mathrm{ml}$ glass vial. The reaction was initiated by manually injecting $1 \mathrm{ml}$ of $50 \mathrm{mM}$ phosphate buffer at the desired $\mathrm{pH}$, and the light emission was measured (13). The integrated value of light emission during the first minute after the start of the reaction was taken as the luciferase activity.

LBP activity was determined based on the fact that at $\mathrm{pH} 8$, it competes with luciferase for the luciferin, thereby decreasing light emission in the reaction $(5,26)$. For this measurement, the pH-insensitive Lp D2 luciferase with 4-His replaced by Ala (see above) was brought into contact with either the luciferin alone or the mixture of the luciferin and the LBP protein of interest by an injection of $1 \mathrm{ml}$ of assay buffer at $\mathrm{pH}$. The difference in the activities in the presence and the absence of the LBP was used as a measure of the LBP activity.

This article is dedicated to Therèse Bremer Wilson with profound gratitude for her important contributions to scholarly activites in the Hastings laboratory over the last 35 years, including insightful suggestions for experiments and helpful review of this manuscript. We thank Dr. Ed Busky and Cammie Hayett of the University of Texas Institute of Marine Sciences at Corpus Christi for helping to collect samples. The imaging machine was provided by Xenogen. This research was supported in part by National Science Foundation Grant 0343407 (to J.W.H.).

13. Li L, Liu L, Hong R, Robertson D, Hastings JW (2001) Biochemistry 40:18441849.

14. Pellegrini M, Marcotte EM, Yeates TO (1999) Proteins 35:440-446.

15. Nawata T, Siboaoka T (1979) J Comp Physiol 137-149.

16. Long M, Betran E, Thornton K, Wang W (2003) Nat Rev Genet 4:865-875.

17. Wang W, Yu HJ, Long MY (2004) Nat Genet 36:523-527.

18. Eckert R, Reynolds GT (1967) J Gen Physiol 50:1429-1458.

19. Eckert R (1965) Science 147:1140-1145.

20. Nicolas M-T, Nicolas G, Johnson CH, Bassot J-M, Hastings JW (1987) J Cell Biol 105:723-735.

21. Thompson EM, Nafpaktitis BG, Tsuji FI (1988) Comp Biochem Phys A 89:203-209.

22. Bugos RC, Chiang VL, Zhang XH, Campbell ER, Podila GK, Campbell WH (1995) BioTechniques 19:734-737.

23. Kumar S, Tamura K, Nei M (1994) Comp Appl Biosci 10:189-191.

24. Olmstead JB (1981) J Biol Chem 256:11955-11957.

25. Knaust R, Urbig T, Li L, Taylor W, Hastings JW (1998) J Phycol 34:167-172. 26. Krieger N, Hastings JW (1968) Science 161:586-589. 